\title{
Like marriage, without the romance
}

John Portmann University of Virginia, Charlottesville, USA

\begin{abstract}
Physicians and philosophers have contributed to the field of medical ethics several different paradigms for the physician-patient relationship. Here I suggest another: marriage. Patients usually enter into relationships as we enter marriage: we allow our high hopes to obscure the possibility of deep disappointment. The argument of the essay encourages renewed focus on the contractual element of physician-patient relationships.

(Fournal of Medical Ethics 2000;26:194-197)
\end{abstract}

Keywords: Relationship; malpractice; emotions; hope fear; contract; covenant; marriage; expectations

Try as we might to control our emotions, they sometimes withstand even our best efforts. Particularly in medical care, fear and hope abound. Physicians and patients both would do well to consider how emotions can infiltrate our efforts to think clearly.

What kind of physician could keep her emotions under lock and key? Only a physician most of us would prefer to avoid. A reading of Aristotle, who links pity to fear, suggests that compassionate physicians may pity their patients for two reasons, one other-regarding (sadness about a patient) and the other self-regarding (fear that one could end up in the same condition). In the Rhetoric Aristotle writes that, generally speaking, the same misfortunes that cause us to pity others cause us real fear when they happen to us. ${ }^{1} \mathrm{He}$ does not exactly say that fear and pity differ only in regard to whether the misfortune happens to us or to someone else; his point is rather to balance these psychological reactions on a fulcrum of emotional closeness. These emotions arise in the context of caring for others: Aristotle believes that we can only fear for other people or pity them if they matter to us in some important sense. ${ }^{2}$

Sick people want help. They naturally invest hope in the physicians they find. I want to examine the idea that patients as a group dislike thinking unpleasant thoughts (no doubt physicians do too, although probably less so in the health care setting). A study demonstrated that most patients who have not discussed preferences for end-of-life care do not want to do so. ${ }^{3}$ Most patients and physicians have not discussed end-of-life decisions, and most patients have not completed advance directives. A culture heavily invested in "the power of positive thinking" produces patients who may well resist thinking about the possibility that their physicians will disappoint them. Do caring physicians reinforce their patients' natural aversion to bad thoughts?

It is impossible to answer so general a question definitively. However, something approximating an answer emerges from comparing the patientphysician relationship to marriage. Various scholars have pointed out the peculiarity of our relatively recent and predominantly Western notion that marriage should be based on love. ${ }^{4}$ Even after the Roman Catholic Church came to characterise marriage as a sacrament (that is, as a means through which to encounter God), many families regarded marriage as a largely economic arrangement. The romantic or erotic aspect aside, marriage more closely resembles patientphysician relationships than friendship, for friendship does not involve any sort of legal agreement. The stakes in both marriage and patient-physician relationships loom quite a bit higher than in friendship.

It is entirely appropriate that patients and physicians alike hope for a happy ending. For this reason, patients and physicians have something important to learn from prospective spouses.

\section{When patients and physicians meet}

Virtually all patients hope, and some even hope against hope. Few surrender immediately to their illnesses. Biotechnology helps patients to hope, even to hope against hope. Broad-based astonishment at the extraordinary progress of medicine in the past few decades is a cultural phenomenon for which we must develop a feeling if we are to understand the expectations of patients.

Physicians naturally hope for the best for their patients as well. That physicians should establish better "connections" with their patients has become a regular theme in the literature of biomedical ethics. ${ }^{5}$ Some writers in this genre do a better job than others of bringing out the potential risks of establishing closer relationships with patients. One physician claimed in the fournal of 
the American Medical Association: "for me fulfillment comes from the sudden intimacies with total strangers-those moments when the human barrier cracks open to reveal what is most secret and inarticulate". ${ }^{6}$ Another physician has strongly urged empathy in clinical encounters and has argued that passion is a part of that empathy. ${ }^{7}$

Some patients will expect their physicians to fill the role of a powerful paternal or maternal figure. By the same token, some physicians are only comfortable in relationships where they are taking care of and controlling others. ${ }^{9}$ Even aside from relatively marginal cases, emotions can pervade physician-patient relationships.

No matter what else it aims to be, the patient-physician relationship is a contract involving the exchange of money and services. Dr Timothy Quill has specified that four assumptions underlie the physician-patient contract: both the physician and the patient have unique responsibilities; the physician-patient relationship is consensual, not obligatory; both the physician and the patient must be willing to negotiate, and physician and patient each must gain something in their encounters. ${ }^{10}$ Nothing in this list contradicts a contractual description of marriage, which similarly stands on an exchange of money and services.

A number of experts in the field of biomedical ethics agree that the patient-physician relationship is "more a covenant than a contract". This is not to say, however, that consensus exists on this point. The Western institution of marriage represents both a covenant and a contract. Broadly speaking, Western culture leads people to view matrimony as a covenant and, in so doing, encourages them to ignore the contractual nature of the institution. Married persons who face divorce for the first time frequently come to view the institution in a very different way - that is, as a contract. Patients disappointed by their medical care may well take a similar mental turn. Many medical malpractice suits begin in this way.

\section{When prospective spouses meet}

Aristotle marries fear and pity in a way that requires emotional proximity. Although Aristotle does not mean or even mention marriage, he introduces the notion of affective ties in a way that makes marriage relevant to a discussion of what happens when physicians and patients meet. Just as prospective spouses focus on positive outcomes, so too do prospective physicians and patients work from a natural aversion to bad thoughts. What can physicians and patients learn from the legal institution of marriage?
The American legal scholar Lynn Baker has usefully illuminated the contractual nature of marriage in various articles. She has pointed out that although there is little about the present legal procedures for getting married that would cause one to think that a contract is being entered into, the law has long explicitly characterised marriage as a legal "contract" among husband, wife, and the state. ${ }^{11}$ When one marries, one agrees to be bound by the various laws that constitute the implied terms of the marriage contract. At the time one applies for a marriage licence, the state necessarily possesses the most complete possible "knowledge" of the legal terms of the marriage contract; however, it generally does not take any affirmative action to disclose even a portion of that information to the parties requesting to be married. Nor does the state require the spousesto-be to demonstrate that they have grasped the terms of the contract into which they are about to enter. I take Baker's point to apply to European marriages as well as to American ones, although I acknowledge differences between the two (for example, monetary settlements for both divorce and malpractice tend to be higher in the US).

\section{Negative outcomes}

Baker's thinking raises a question regarding informed consent for persons engaged to be married that extends naturally to persons in search of a physician: why is it that the law does not compel patients to learn before choosing what the legal character and consequences of their acts are and, further, help them to predict with reasonable certainty the outcome of any subsequent adjudication regarding possible negative outcomes? Baker has elsewhere argued that people simply do not wish to consider the possible negative outcomes of a marriage contract. She has written: "[W]e ... seem to believe that knowledge of the law, even taken alone, is not always and unambiguously better than ignorance. For sometimes that knowledge comes at the cost of dimming, if not entirely dispelling, our most precious ideals and cherished hopes. And that price is one we cannot afford to pay." 12 Prompting patients and potential patients to view their relationships as a covenant may be grounded in, and appeal to, their hope for recovery and may result in a susceptibility to overlook the contractual nature of their interaction with a physician.

In a separate work Baker surveyed marriage licence applicants and law students about their knowledge of divorce statutes, knowledge of the demographics of divorce, and expectations for their own marriage. ${ }^{13}$ Both groups had largely incorrect perceptions of the legal terms of the 
marriage contract as embodied in divorce statutes, but both groups had relatively accurate, if sometimes optimistic, perceptions of both the likelihood and the effects of divorce in the population at large. These same individuals expressed thoroughly idealistic expectations about both the longevity of their own marriages, as well as of the consequences of divorce. Increasing individuals' knowledge of divorce statutes through a course on family law did not diminish this unrealistic optimism. Baker's findings strongly suggest that the sense of surprise that frequently attends divorce may be a result of systematic cognitive biases rather than a lack of information about divorce.

Respondents' predictions for the permanence of their own marriages and the consequences should they be divorced were much more optimistic than their perceptions of the likelihood and effects of divorce for others. For example, although their median response was an accurate estimate that fifty per cent of American couples who marry will divorce, the median response of the marriage licence applicants was $0 \%$ when assessing the likelihood that they personally would divorce.

\section{Aversion to bad thoughts}

After reading Baker's work, it is not difficult to understand why prenuptial contracts are so rarely used and, later, their lack so often regretted. Baker's work may have something to say to clinicians who ponder the reasons why so few people have drawn up advance directives about end-of-life health care. The kind of thinking about patientphysician relationships outlined by the articles I have cited discourages questions about malpractice or unhappy endings. Just as persons tend strongly to dislike considering possible negative outcomes of matrimony, so might they strongly dislike thoughts of negative outcomes with physicians.

Perhaps the easiest way to avoid thinking of an unappealing possibility is to ignore the contractual nature of the relationship and to view that relationship as a loving covenant instead. For physicians, the importance of negotiating a proclivity to pity or feel compassion for her patients would seem to consist at least in part in recognising her own fears. The advantages to thinking of physician-patient relationships in largely business terms extend to patients as well: frank discussion of bad news grows out of genuine concern for patients. It would be cowardly for a physician to crouch with a patient behind illusions of safety or veils of undaunted optimism.

What I advocate, then, is a renewed focus on the contractual element of physician-patient relation- ships. There are, of course, objections to the view that a physician-patient relationship is more a contract than a covenant. Those who defend the covenant model at times criticise contracts as too individualistic, and at times as minimalistic (specifying only the moral minimum of the relationship). At other times the contract model is rejected as externalistic (emphasising external actions rather than the spirit of the relationship and the character of the agents), and legalistic (focused on legal enforcement). Those who prefer to discuss the patient-physician relationship in the language of loyalty and faithfulness rely on virtues rather than on principles and rules. Robert Veatch and other defenders of a contract model reply that a covenant is only a special form of contract that emphasises moral relationships such as fidelity; they also maintain that medical ethics is best understood in terms of a broader nexus of contracts between society, the professions, and patients. Tom Beauchamp and Jim Childress have brought this debate to life in various editions of their influential Principles of Biomedical Ethics. ${ }^{14}$

Perhaps the strongest justification for framing physician-patient relationships in terms of a covenant is that covenants seem to come down to one-sided promises between someone with power and/or wealth and someone less powerful or wealthy. In the last three decades, though, legal recourse has greatly increased the power of a patient to fight a physician. The very idea of a malpractice suit impoverishes the covenantal model of physician-patient relationships. That said, I have argued that patients tend to resist thinking of malpractice suits, more or less in the same way that the betrothed resist thinking about divorce.

Although my sympathy lies with Veatch ultimately, I think that reducing relationships between physicians and patients to any single metaphor (for example, confessor, parent, friend, spouse, expert consultant) or model will prove inadequate. The complexity of health care and the moral principles and rules that should govern such relationships compel us to think in broader terms than just contracts and covenants. One need not take a position in the debate over whether the patient-physician relationship is more a covenant than a contract in order to conclude that the contractual dimension of the relationship can usefully offset the marriage of pity and fear Aristotle illuminates.

\section{The ethics of hoping}

The problem of many patients includes an importantly psychological component: illness. threatens their connection to the vividness and vibrancy of 
the world. New medical technologies and the faith patients have in them make it easier than ever to seek to avoid the natural unpleasantness of thinking about illness. Hope seems ever more rational. Physicians ought to be aware of the potential pitfalls inherent in the psychological aspects of physician-patient relationships. And those writing in the fields of biomedical ethics and medical humanities ought not to disguise or sugarcoat those potential pitfalls. Managing the expectations of patients' demands sensitivity to their occasional delusions of control and the fragility of hope. Managing the expectations of patients requires vigilance over what Aristotle identifies as a natural tendency to indulge emotionally those we care about.

Fohn Portmann, PhD, (MPhil CANTAB), is Executive Assistant to the Provost at the University of Virginia, Charlottesville, USA.

\section{References}

1 McKeon R. The basic works of Aristotle. New York: Random House, 1941: Rhetoric: 11.5.

2 See reference 1: Rhetoric: 11.8
3 Hofmann JC, Wenger NS, Davis RB, Teno J, Connors AF, Desbiens N, et al. Patient preferences for communication with physicians about end-of-life decisions. Annals of Internal Medicine 1997;127:1-12.

4 Boswell J. Christianity, social tolerance, and homosexuality. Chicago: University of Chicago Press, 1980. Singer I. The nature of love. Chicago: University of Chicago Press, 1984. Hirnature of love. Chicago: University of Chicago Press, 1984 . Hir-
shman LR, Larson JE. Hard bargains: the politics of sex. Oxford: Oxford University Press, 1998

5 Matthews DA, Suchman AL, Branch WT. Making "connexions": enhancing the therapeutic potential of patientclinician relationships. Annals of Internal Medicine 1993;118: 973-8.

6 Radetsky M. Sudden intimacies. Fournal of the American Medical Association 1985;254:1361.

7 Spiro H. What is empathy and can it be taught? Annals of Internal Medicine 1992;116: 843-6.

8 Engel GL. "Psychogenic" pain in the pain-prone patient. American fournal of Medicine 1959;26:899-918.

9 Alder G. Helplessness of the helpers. British Fournal of Medical Psychology 1972;45:315-6.

10 Quill TE. Partnerships in patient care: a contractual approach. Annals of Internal Medicine 1983;98:228-34.

11 Baker L. "I think I do": another perspective on consent and the law. Law, Medicine \& Health Care 1988;16:257-60.

12 Baker L. Promulgating the marriage contract. University of Michigan fournal of Law Reform 1990;23:217-64.

13 Baker L. When every relationship is above average: perceptions and expectations of divorce at the time of marriage. Law and Human Behavior 1993;17:439-50.

14 Beauchamp T, Childress J. Principles of biomedical ethics. Oxford: Oxford University Press, 1989: 343. I have adapted their summary here.

\section{News and notes \\ Fifth World Congress of Bioethics}

The International Association of Bioethics has announced that the Fifth World Congress of Bioethics will take place at Imperial College, London from 21-24 September 2000

Associated organisations are: The British Association for the Advancement of Science; the British Medical Association; the European Association of Centres of Medical Ethics; the Institute of Medical Ethics; the Millenial Festival of Medicine; the Nuffield Council on Bioethics; the Royal
College of Nursing; the Royal College of Psychiatrists, Philosophy Special Interest Group; the Society for Applied Philosophy; the UK Forum for Healthcare Ethics and Law, and the World Health Organisation.

For further information please contact: Sara Hassen, 5th World Congress of Bioethics, 1 Riverside, St Anne's Road, Bristol, BS4 4ED or email: enquiries@inanyevent-uk.com or use the Congress Website at http://www.uclan.ac.uk/facs/ethics/fifthcon.htm 